\title{
The Timescape of Smart Cities
}

\author{
Rob Kitchin \\ Department of Geography and Maynooth University Social Sciences Institute, National University of Ireland Maynooth
}

To date, critical examinations of smart cities have largely ignored their temporality. In this article, I consider smart cities from a spatiotemporal perspective, arguing that they produce a new timescape and constitute space-time machines. The first half of the article examines spatiotemporal relations and rhythms, exploring how smart cities are the products of and contribute to space-time compression, create new urban polyrhythms, alter the practices of scheduling, and change the pace and tempos of everyday activities. The second half of the article details how smart cities shape the nature of temporal modalities, considering how they reframe and utilize the relationship among the past, present, and future. The analysis draws from a set of forty-three interviews conducted in Dublin, Ireland, and highlights that much of the power of smart urbanism is derived from how it produces a new timescape, rather than simply reconfiguring spatial relations. Key Words: smart cities, space-time, temporality, time, timescape.

对于智能城市的批判性检视, 至今仍大幅忽略其时间性。我于本文中, 从时空的视角关照智能城市, 主张 它们生产了崭新的时间地景并组成了时空机器。本文前牛部分检视时空关系与韵律, 探讨智能城市如何 作为时空压缩的产物与导因, 创造崭新的城市多重旋律, 变更安排计画的实践, 以及改变每日生活活动的 步调与速度。本文后牛部分详细记载智能城市如何形塑时间形式的本质, 关照它们如何重新架构并运用 过往、当下与未来之间的关系。本分析运用在爱尔兰都柏林进行的四十三个访谈集合, 并强调智能城市 主义的力量多牛源自其如何生产崭新的时间地景, 而非仅只是重新组合空间关系。关键词: 智能城市, 时 空, 时间性, 时间, 时间地景。

Hasta hoy, en gran medida los exámenes críticos de las ciudades inteligentes han olvidado su temporalidad. En este artículo, considero las ciudades inteligentes desde una perspectiva espaciotemporal, con el argumento de que ellas producen un nuevo paisaje del tiempo a la vez que se constituyen en máquinas del espacio-tiempo. La primera mitad del artículo está dedicada al examen de las relaciones y ritmos espaciotemporales, explorando el modo como las ciudades inteligentes son los productos de la compresión del espacio-tiempo, a la vez que contribuyen a la misma, crean nuevos poli-ritmos urbanos, alteran las prácticas de programación y cambian el paso y los tempos de las actividades cotidianas. La otra mitad del artículo muestra en detalle cómo las ciudades inteligentes configuran la naturaleza de las modalidades temporales, considerando la manera como ellas reestructuran y utilizan la relación entre pasado, presente y futuro. El análisis se apoya en un conjunto de cuarenta y tres entrevistas llevadas a cabo en Dublín, Irlanda, y destaca que gran parte del poder del urbanismo inteligente se deriva del modo como éste produce un nuevo paisaje del tiempo, en vez de simplemente reconfigurar las relaciones espaciales. Palabras clave: ciudades inteligentes, espacio-tiempo, paisaje del tiempo, temporalidad, tiempo.

$\mathrm{O}$ ver the past decade, many cities around the world have declared the intention to become smart cities. A somewhat nebulous term, in general there are three broad understandings of what constitutes a smart city (Kitchin 2014). For some, a smart city is one in which urban infrastructure and services are managed computationally, with networked digital instrumentation embedded into the urban fabric, producing continuous streams of data that dynamically feed into management systems and control rooms, creating new forms of governmentality (Vanolo 2014; Luque-Ayala and Marvin 2016). For others, a smart city is one in which the strategic use of information and communications technology (ICT) produces smarter citizens, workers, policy, and programs; fosters innovation, economic development, and entrepreneurship; and produces urban resilience and sustainability (Giffinger and Pichler-Milanović 2007). A third position casts a smart city as one adopting an ICT-led, citizen-centric model of development that fosters social innovation and social justice, civic engagement and activism, and transparent and accountable governance (de Lange and de Waal 2013). These three understandings are not mutually exclusive, and smart city strategies seek to blend elements of them in varying proportions and emphases. 
Accompanying the development of a global smart cities movement has been critical analysis that examines the nature and consequences of smart urbanism. To date, such analysis has focused primarily on how the technologies and processes of smart urbanism reconfigure modes of governance and urban development and reshape the production of space and spatiality. For example, Thrift and French (2002) outlined the automatic production of space by software-enabled technologies, and Dodge and Kitchin (2005) detailed the transduction of space by code and the creation of new spatial formations such as code/space. S. Graham and Marvin (2001) set out how networked infrastructures produced forms of splintering urbanism, and S. D. N. Graham (2005) documented the creation of software-sorted geographies. Foth (2009) and Elwood and Leszczynski (2013) detailed how urban informatics and spatial and locative media are producing new spatial imaginaries and knowledge politics. Shelton et al. (2015) examined the "actually existing smart city" and how networked technologies are enrolled in the neoliberal production of urban space. Datta (2015) detailed how the smart urbanism agenda is creating a set of contested spaces in India as land is reallocated for the development of 100 new masterplanned smart cities. Mattern (2017) provided a media archeology of the ways in which smartness has been folded into and mediates urban spaces.

In contrast to the focus on space and spatiality, there has been comparatively little consideration of the relationship between the development of smart cities and time (although there is a well-established literature exploring the temporality of cities more broadly and the co-constitution of space, time, and technology; see Parkes and Thrift 1980; Massey 1992; Castells 1996; May and Thrift 2001; Hassan and Purser 2007; Edensor 2010). Where time and the temporality of smart cities have been examined it is usually with respect to the increasingly real-time nature of urban management and governance, in which streams of big data flow into urban control centers and are used to manage urban systems based on present conditions and how such data are parsed to citizens through spatial and locative media accessible via smartphones (e.g., de Waal 2014; Kitchin 2014; Leszczynski 2015a; Coletta and Kitchin 2017; de Lange 2018), although Rose (2017) discussed the temporalities of posthuman agency in the digitally mediated city, and the essays in Datta and Shaban (2016b) detailed how speed and the temporal changes wrought by smart city initiatives are a critical element in enacting "fast urbanism" in the Global South.

In this article, I examine more thoroughly the temporality of smart cities and how smart city technologies are reconfiguring the space-times and spatiotemporal relations of cities to produce a new timescape and how temporality is deployed to imagine and drive smart city initiatives. Adam (2004) described a timescape as a cluster of associated temporal relations (time frames, temporality, tempo, timing, time point, time patterns, time sequencing, time extensions, time past, present, and future) that are implicated with each other (although not necessarily of equal importance) and work to produce a particularized temporal landscape. She contended that the notion of "scape" is important because it "indicates, first, that time is inseparable from space and matter, and second, that context matters" (Adam 2004, 143). I contend that smart cities are space-time machines, with networked infrastructure and smart city technologies significantly disrupting temporality as well as spatiality to produce a new set of space-time relations.

The analysis draws on a set of forty-three interviews conducted with smart city stakeholders (seven from local authorities, nine from a state agency, six from large companies, three from small and mediumsized enterprises [SMEs], seven university researchers, five from civic groups, three from lobby groups, and one politician) in Dublin undertaken between February and December 2015 as part of a large European Union-funded project. The interviews sought to understand the extent to which Dublin was becoming a smart city and was not specifically designed to examine notions of time and temporality. The interest in time was sparked by the first interview coded in which several registers of timepeak times, evolutionary times, cyclic times, real time, and social time-were mentioned.

Well, I suppose in common with most large cities we have had a traffic control center for a number of years. So our first traffic control center was built around 1987 or even 1986 and it has gone through several different iterations and expansions and so on. The latest version of it was considerably changed in 2013. The traffic management center itself is a twenty-four-hour, sevenday-a-week operation; it is staffed by our own control room operators. At peak times it has people from AA Roadwatch, which is the motoring organization here. We have facilities for the police and the public 
transport service to be here as well, so at the moment during the run-up to the Christmas busy time they are in there every day. So we have somebody from the police and somebody from the public transport operators. We also have our own dedicated radio station which broadcasts six hours a day, 7:00 to 10:00 and 4:00 to 7:00. And the idea of that is it provides very detailed traffic information to people in very much a real-time fashion using all the cameras and the technology that we have in the traffic control center. (SDP43, Senior executive manager, Local Authority, italics added)

Examining the other interviews it was apparent that time was a common refrain. The interviews were thus coded with respect to temporal concerns, focusing on the configuration of spatiotemporal relations and the relationship among past, present, and future in the production of smart cities.

\section{Temporal Relations and Rhythms}

It has long been argued that networked ICTs radically reconfigure space-time relations, leading to significant time-space compression, a transformation in the concatenated temporal rhythms of cities, and a change in the pace and scheduling of everyday life (Castells 1996; S. Graham and Marvin 2001). Such temporalspatial shifts are a key aspect driving the creation of smart cities (to overcome space with time to produce economic development, accumulate capital, and create efficiencies in the delivery of public services); the form, functioning, and governance of urban and regional systems (as densely interconnected, interoperable, resilient, sustainable systems); and in the experience of living and working in smart cities (as alwayson, hypermobile, performative places).

\section{Time-Space Compression: Convergence and Distanciation}

Time-space compression consists of two related processes. Time-space convergence is the shrinkage in time taken to communicate or travel between locations (Janelle 1968). New communication and transport technologies and infrastructures have eroded successively the friction of distance by fulfilling Marx's (1857) maxim that capital creates new markets and accumulates by "annihilating space by time." Since the invention of the telegraph in the mid-nineteenth century, there has been a marked acceleration in the time and volume of information traversing between distant places, culminating recently with global, mobile, and ubiquitous realtime communication to most locations on the planet. In turn, time-space convergence has acted as a key driver of modernity and globalization, enabling significant time-space distanciation, a synchronicity between places wherein activities are disembedded from local contexts and reorganized across large distances so that locales become increasingly integrated and interdependent (Giddens 1984). For example, companies have been able to organize their operations across the globe, with workers in one location being overseen from another and vast, complex logistics networks being managed centrally.

Time-space convergence and distanciation have had profound effects on the global urban system and on the form and functioning of urban locales and regional development. In contrast to the death of distance thesis, which hypothesized networked ICTs erasing the effects of geography (Cairncross 1997), time-space compression is uneven and there are other factors that affect the location of industry, such as property and labor costs, business regulations, and quality of life (cost of living, congestion, etc.; Dodge and Kitchin 2000). On the one hand, there are centralizing forces, with companies receiving significant spillover effects from the urban agglomeration of ICT networks, talented labor, and density of complementary businesses (Castells 1996). On the other hand, there are decentralizing forces, with many office activities, business services, and production centers shifting to lower order cities or to the edges of metropolitan areas to take advantage of no loss of time in delivery but lower rent and labor costs, reduced worker turnover, and a skilled, suburban labor pool (Castells 1996). This decentering requires centralized command-and-control and deepens time-space distanciation and the interdependencies between locations. The drive to create smart cities is in part a continued playing out of such processes, with some cities utilizing smart city initiatives to consolidate their competitive advantage or to reposition themselves in the global urban order by capturing inward investment, growing indigenous industry, and creating startups by providing a sufficient agglomeration of ICT infrastructure and attracting sufficient talented labor and creating new markets of urban ICT infrastructure and management (e.g., new Internet of Things platforms), real estate investment, and urban knowledge (e.g., consultancy and apps). 
With respect to Dublin, since the late 1980s the city has benefited from the processes of centralization and decentralization produced by space-time compression, using networked services industries to drive rapid economic growth. Breathnach (2000) detailed that initially the Irish state pursued a strategy of entrepreneurial urbanism, using planning and tax conditions alongside significantly improved ICT infrastructure to attract low-skill services and high-skill manufacturing to replace an ailing branch-plant economy (with functions decentered predominantly from the United States to Dublin). In the 2000s, the state sought to attract higher skill service jobs and the European headquarters of global tech companies, creating centralized hubs of ICT-led economic activity, with Dublin seeking to implement a creative cities strategy and to leverage the time-space distanciation of being plugged into the global informational economy (Kitchin and Bartley 2007). In the 2010s, the focus has shifted to Dublin becoming a smart city in large part to drive economic recovery after the financial crisis, with the city creating an open data portal and a new unit-Smart Dublin - to coordinate smart city initiatives across four local authorities and sponsoring hackathons and procurement-by-challenge initiatives designed to create new startups, as well as enabling experimental urbanism that makes city spaces available to companies to trial and test new products as a way of attracting new foreign direct investment (Coletta et al. 2018). This urban entrepreneurial strategy of pursuing a networked economy has been highly successful, moving Dublin and Ireland from the European periphery, with the second lowest gross domestic product (GDP) in the European Union in 1987, toward the center, with the second highest GDP by the early 2000s (Breathnach 1998; Kitchin and Bartley 2007), and has facilitated economic recovery after the property-led financial crash of 2008. Moreover, it has led to dramatic urbanregional restructuring, with a large growth in population, extensive suburbanization of housing and office and industrial premises, and polycentric development. Overcoming peripherality with time has thus had a profound effect on the city.

\section{Temporal Rhythms}

Although time-space compression disrupts natural, social, and clock time by producing instantaneous time, it does not erase them or local instantiations of time (Crang 2007). As Lefebvre
(2004) and others (see Edensor 2010) have argued, cities and everyday life unfold through cycles of polymorphic and concatenated temporal rhythms that produce a sense of continuity, stability, or disjuncture. Lefebvre identified two main types of rhythms. Linear repetitions are "imposed structures" through social practices such as clock time and timetables, whereas cyclical repetitions are "lived time" originating in "nature: days, nights, seasons" (Lefebvre 2004, 8). May and Thrift (2001) thus noted that people's sociospatial practices are rhythmically conditioned in at least four ways: (1) natural cycles, such as the diurnal cycle, seasonal change, turning of tides, and bodily rhythms; (2) social discipline, such as religious or work or official timetables or mealtimes at home; (3) instruments and devices, such as sundials, clocks, video recorders, transportation, and smartphones; and (4) texts that codify and shape one's understanding of time, such as timetables. As Lefebvre (2004) noted, people are often encountering and coproducing several rhythms simultaneously such that cities host a series of "intersecting rhythms, including the polyrhythmic [multiple], eurythmic [harmonious and stable], isorhythmic [equal and in sync] and even arrhythmic [out of sync and disruptive] measures as well as secret, public, internal and external beats that comprise the symphonic everyday" (Conlon 2010, 72-73). The urban fabric thus pulsates rhythmically, producing a "topology and texture of temporality" that frames and mediates urban life (Crang 2001).

Many smart city technologies, such as urban infrastructures mediated by software, the Internet of Things, and control rooms, are designed to augment and regulate the multiple rhythms of cities, to limit arrhythmia and produce eurythmic systems that maintain a refrain. Such technologies are "algorithm machines" (Gillespie 2014) that perform new forms of algorithmic governance, working to monitor and manage automatically, quickly, efficiently, effectively, and inscrutably how systems are performing and the space-times of cities to produce consistent patterns of rhythms. In effect, algorithms act as "algorhythms" producing "measurable time effects and rhythms" (Miyazaki 2012, 5). Coletta and Kitchin (2017) demonstrated how the rhythms of urban systems and the space-time unfolding of place are algorhythmically mediated through a case study of a traffic control room that processes real-time data generated by a dense network of sensors and cameras to 
automatically sequence traffic lights and synchronize the flow of traffic and of a sound network used to monitor and model noise pollution. For one respondent, such algorhythmic systems are useful because they seek to capture and regulate the "heartbeat of the city" (SDP42). This information can also be used to predict and calibrate future flow and to inform citizens in real time about how to synchronize their own actions with the temporal rhythms of urban services.

The temporal rhythms of cities can also work over longer time frames, and some of the respondents contended that Dublin's desire to become a smart city is tempered by mis-synchronization between rhythms with different refrains and durations. For example, a manager with a large multinational company noted:

[I]f you think about a city, let's take Dublin as a specific example, they have already celebrated their 1,000th year anniversary, so when you think about the physical city you have to think in terms of the pulse rate being thirty years; a heartbeat in Dublin terms is thirty years because that is how long it takes to conceive of and build a bridge. You are looking at timelines that are not driven by electronic Internet time clocks. ... [D]ecision making needs to be made in the sense of I am investing in a piece of infrastructure that must last for 100 years. [In contrast], homelessness ... is a very immediate sharp focus problem, depending on government policy it may be more or less of a problem in a particular month, year and so on. So there are many different timelines and tracks within a city. ... So you can't simply come in and say, we are going to make a superhighway to the docks. That doesn't happen. And it doesn't happen in anything less than twenty years anyway. (SDP29, italics added)

Similarly, a state agency official stated that their organization often talked

about the clock speed of tech and the clock speed of cities. ... [I]f a new technology emerges every two years but a city council takes five years to build a case flow starting a new department there is going to be a real problem. ... I have great respect for all those forward thinkers in [a local authority] but stick them in a room full of Google people and they are just on a different clock speed, the culture is completely different. ... [I]f you walk into any room in the tech industry, most of the people in the room, if you ask them, "Will you still be here in five years' time?" the answer is no. ... So they need to complete their projects on six-month timelines. ... [I]t is a huge amount to ask the city to act in the same clock speed. (SDP37)
Becoming a smart city then necessitates seeking to harmonize and synchronize the temporal rhythms of a diverse set of practices and processes, something that can be difficult to do because of established routines and institutional cultures. This can bring the city out of line with what other innovative cities might be doing. For example, some of the respondents discussed whether Dublin was out of sync or ahead of or behind the curve with respect to becoming a smart city. In general, the consensus was that Dublin was behind the curve, needing to catch up with new technical innovations, policy, and practices if it wanted to be a leading smart city and to gain the benefits of being an early adopter. In other words, it needed to shift from being a second-mover adopter, in which the risks of investment are lower because a technology is established, to a first-mover innovator where technology is immature but the city gains from enhanced space-time relations, economic spillovers, and innovations that can be exported. Smart Dublin seeks such first-mover advantage through running procurement-by-challenge schemes aimed at encouraging startups and SMEs to tackle city problems and by facilitating urban experimentation through testbedding (Coletta et al. 2018).

\section{Scheduling, Pace, and Tempo}

In his seminal work on time-geography, Hägerstrand (1970) argued that people moved and planned their lives along space-time trajectories. Networked and mobile technologies provide a new set of tools to mediate space-time trajectories and alter the nature of constraints that delimit everyday movements. With respect to the latter, Global Positioning Systems (GPS) and locative and spatial media are starting to become ubiquitous in the Global North and they create new tools for managing spatial behavior; at the same time, movement and location are increasingly open to real-time nudging, surveillance, and forms of discipline and control (Kitchin et al. 2017). As Crang (2007) noted, such technologies are having pronounced effects with respect to the constitution of individual time-geographies in the smart city, producing "faster" and more temporally flexible subjects.

Time-Shifting, Scheduling, and Planning. For Hassan (2003), the creation of network time-time fragmented and made simultaneous across globally connected digital networks-is fundamentally 
changing the meaning and experience of time. Just as the clock shifted our relationship with time from social and natural registers to an abstract mechanical register, networked time undermines, replaces, and coexists with clock time. Set meal times, clocking in and out, timetables, prearranged meetings, and so on, built around the measure of a clock, are traded for greater temporal flexibility. Adam $(2007,1)$ thus contended that networked time is "globally networked rather than globally zoned. It is instantaneous rather than durational or causal. It is simultaneous rather than sequential." It shifts the scheduling and planning of activities and events from specific times and places to any time, any place.

For example, in recent years, mobile phones and social and spatial media have altered the practices of coordination, communication, and social gathering in space, enabling on-the-fly scheduling of meetings and serendipitous encounters by revealing the location of nearby friends (Sutko and de Souza e Silva 2011), as well as new forms of activism such as swarming and flash mobs (Willis 2016). They have also enabled access to information about the realtime conditions of transportation networks, such as delays and congestion, enabling route planning to be taken in context and rerouting to optimize travel time. Spatial search and location-based services provide information and recommendations concerning local businesses, enabling dynamic and contextual spatial choice and decision making rather than advanced search and planning. Moreover, they enable time shifting to occur, with diaries becoming flexibly organized around unfolding events, such as people being delayed or unexpected meetings. All these tasks can be undertaken in situ, on the move and in real time, augmenting a whole series of activities such as socializing, shopping, wayfinding, sightseeing, protesting, and so on (Leszczynski 2015b; Kitchin et al. 2017). Indeed, beyond mobile communication via phone or social media, there are now a plethora of urban apps that are designed to help mediate the experience of living in and moving about cities.

Sutko and de Souza e Silva $(2011,811)$ thus suggested that location-aware technologies are replacing the proactive management of time and "the clock as a medium for coordinating meetings in space." As such, Wilson (2012) contended that mobile, spatial, and locative media are producing conspicuous mobility and are restructuring urban experiences by figuring people's mobilities. As space-time interactions become more flexible and fluid, new mobilities and spatial practices reshape how places are experienced. Indeed, how we understand, relate to, move through, coordinate, and communicate in, interact with, and build attachments to space and place is altered (Kitchin et al. 2017; Rose 2017). For example, a number of the interviewees discussed how real-time passenger information (RTPI) for public transport was reshaping their travel.

[T] he live updating of bus locations and linking that to a mobile app, I think, is a quiet revolution. ... If you talked to anyone in Dublin a few years ago about the public transport ... they will tell you jokes and stories about the timetables-you might as well be reading fairy tales and all this kind of stuff. That has now changed because I could sit at home, I could look at the bus app and I can see at my stop around the corner from my house there is a bus going to be there in five minutes or twenty minutes or whatever. ... [T] he lack of predictability has been ... a big chunk of that problem has been taken away. (SDP39, university researcher)

Further, beyond individual use, smart city technologies, such as a traffic control room, can alter the scheduling of traffic lights in real time to coordinate and prioritize the movements of certain groups of people or modes of transport. For example, the supervisor of the Dublin traffic control room (SDP43) remarked:

As you start to move nearer and nearer to the city you
are starting to have competing demands so you want to
make sure that pedestrians get a good share of the
green time. You want to make sure cyclists can be
catered for. And then as you come right into the heart
of the city you are trying to more and more prioritize
walking, cycling, public transport rather than just
simply car use. Likewise, city managers can dynamically schedule workflows around the sites of events, as detailed by one local authority administrator (SDP20):

We have internal apps which our staff would use out in the public realm, so after the bonfires of Halloween the guys go around with their mobile devices, point them at the site of where the bonfire was, take the photo of it, it picks up the GPS, takes the predefined check boxes and fields and whatever else, bang, it goes back into the corporate system. 
The smart city then is enabling a breaking free from, or the active management of, clock time by facilitating real-time decision making and allowing one cognizant and flexible with respect to timetabled time, such as bus and train schedules or work schedules.

Pace and Tempo. In addition to peoples' timegeographies becoming more flexible and fluid, it is argued that they are accelerated and gaining tempo. The use of networked technologies is creating a faster and busier world by enabling tasks to be undertaken more efficiently and a state of hyperconnectivity to exist (Virilio 1997). Not only are temporal rhythms and relations faster but the rate of technical and social change seems to have accelerated with a succession of new innovations. Rosa (2003) described three forms of acceleration.

The first form is the acceleration of the pace of life, in which there is a decrease in the time needed to undertake everyday processes and actions of production, reproduction, communication, and transportation. Somewhat paradoxically, such a speeding up does not lead to an increase in free time, with the additional time colonized by other activities. Wajcman (2008) contended that this is because the "always on" nature of networked technologies, particularly mobile media and the Internet, enables "dead time" to be made "productive time." Moreover, the time-shifting property of networked technologies expands the possibilities for time-deepening activities, such as multitasking (Crang 2007). As a consequence, ICTs often produce ever-moreextended and complex networks of tasks to attend to, producing time crunches in which it never feels like there are enough hours in the day to do all of the things needed (Hassan 2007). Although ICTs hold the promise of helping people cope with what Southerton and Tomlinson (2005) termed temporal density (i.e., intense, overlapping temporal rhythms caused by multitasking and the fragmentation of time), they compress and fragment time further (Crang 2007).

The second form is technological acceleration, the speeding up of technical processes, such as the rate of data processing, the rapidity of communication, and the work pace of manufacturing machines. For example, the head of a state agency stated:

Just speaking purely as a private citizen, when I think about what I can do on my phone now compared to five years ago, be it Hailo or the buses or looking at the localized weather hour by hour and all that stuff, the pace of change is so massive. (SDP24)

It is this acceleration that is driving the processes of time-space compression, although it is tempered by frictions such as congestion and bandwidth. It also creates efficiencies in the delivery of services by saving time. For example, one of the respondents (SDP38, manager, multinational company) discussed some work on increasing traffic flow with respect to buses:

Whatever particular bus it was, they have reduced the time on this stretch of road by 20 percent. ... If you ... achieve 20 percent across the full route ... what are the implications of that? So what does that do for the GDP of the city? ... A lot of the things can be multiplied. So you run a solution on this junction controller or this bus route and you apply the logic of that ... to forty junctions and fifty bus routes. And every bus then, all of a sudden, is 20 percent quicker.

Moreover, as Wajcman (2008) noted, new technologies do not simply speed up processes and actions or save time but can change their nature and meaning, as well as introduce new material and cultural practices. In other words, people are not simply doing the same things at a faster pace but are performing new kinds of tasks and producing new sociospatialtemporal relations.

The third form is acceleration of social change, in which social relations (e.g., attitudes, values, practices, habits), structures (e.g., communities, workplaces), and institutions (e.g., public services) increasingly lack stability and change in constitution on an increasing basis (Rosa 2003). Whereas in the Global North these shifts are predominantly social changes, in the Global South the acceleration of change is occurring across all domains of life and involves large migrations and rapid urbanizationthe production of what Datta $(2016,1)$ termed "fast cities." Smart cities cast urbanization as an opportunity, not a challenge, with the speed of change being met by an acceleration in response, enabling emerging crises to be met and dealt with (Datta 2016). So, although smart city technologies work to accelerate life, they are also pitched as the means to measure, manage, and cope with such an acceleration. Fast urbanization thus speeds up, optimizes, and makes more efficient administration, planning, service delivery, policy formation, and infrastructure provision (Datta 2016), seeking to produce rapid transitions and "compressed modernity" (Shwayri 2016). 


\section{Temporal Modalities}

As well as the temporal rhythms and relations of cities being transformed through the drive to make them smart, a key aspect of how smart city technologies work is how they draw on and reconfigure the relationship between the past, the present, and the future. Smart cities seek to leverage information about the past and those generated in real time to more efficiently and effectively manage the present and to anticipate and shape the future. They are technologies that seek to use time as a resource, working across temporal modalities, to produce new space-times in the present and future. Here, I want to consider the temporal work of smart cities with respect to what Adam and Groves (2007) termed past present, present present, future present, and present future. Present is the common denominator because, as Dodgshon (2008) noted, although we apprehend the past (before), present (now), and future (after) as different perceived forms of time, experientially they do not have an existence outside of the present. Four ways in which we know the past, present, and future from the present are hindcasting (building a model of how things worked in the past), nowcasting (using real-time data to predict present and very near future conditions), forecasting (using the present to predict the future), and backcasting (working backward from a desirable future scenario to identify policies and interventions to lead from the present to that future).

The latter two, in part, distinguish present future and future present. The present future, according to Adam and Groves (2007), is the future from the standpoint of the present. It is the future to be created, which unfolds from past and present trends, the result of given and embedded structures and individual embodiment (Poli 2015). Adam (2008) thus noted that the present future positions the future as ours "to shape and create," with current economic, political, and institutional practices "tak[ing] from the future for the benefit of the present." Future present, on the other hand, uses the future in the present, using possible or anticipated future outcomes to rethink present practices that then reshape the future created (e.g., using predictions of climate change outcomes to change policy and activities in the present to realize a different future; Adam and Groves 2007; Poli 2015). The future present acknowledges that our present actions potentially affect future generations and we can act morally and ethically to create a different world (Adam 2008). Smart cities are the result of the anticipatory logics of future present (White 2016) but by and large work to create the present future.

\section{Past Present}

There is a long history of urban data being generated as a way to understand and manage cities. Much of these data, and the subsequent information produced from them, is preserved in archives and repositories. These data provide an evidence basis for both understanding past events and conditions and for managing the present and planning the future, with the latter extrapolated from the historical record. Until recently, all evidence-informed analysis was based on past data, even if those data were generated relatively recently. For example, national censuses provide key demographic, social, and economic evidence basis for formulating policy. A census, however, although spatially extensive, only produces a time slice, collected on a single day every ten years. In this sense, they are an example of what Dodgshon $(2008,2)$ termed space ${ }^{\text {time }}$, wherein time is treated in a way subordinate to space. Here, the data primarily deal with geography in time, rather than geography through time. That is not to say that there is no time series to the data but that data sampled every ten years provide only a sense of trends in very broad terms. In most cases, data sets are also sampled across space as well as time. In these cases, time can often be the key aspect of the data, especially for data generated on a weekly, monthly, quarterly, and yearly basis, enabling timeseries analysis. In many cases, spatial and temporal sampling might be one-off endeavors with the data generated to examine a particular issue. One-off data sets have limited utility for smart city initiatives, which engage in continual, ongoing management of urban systems and infrastructure.

In recent years, big data generated at specific sites and on a continual basis using networked sensors, cameras, and other devices have started to be archived. These data provide a new level of granularity (every few seconds, minutes) in the historical records of particular systems. In contrast to space ${ }^{\text {time }}$ data that freeze the world at a particular moment (Dodgshon 2008), big data provide a more continuous record of spatiotemporal processes. Such big data provide an unprecedented "level of control over what is remembered, how it is remembered and what 
influence this can have on contemporary socio-spatial experience," with smart city technologies constituting a voracious breed of "mnemotechnologies" (Kinsley 2015, 169). Prompting discussions on the ethics of forgetting and how such data are utilized (Dodge and Kitchin 2007; Kitchin 2016), the more detailed past present of the smart city offers opportunities with respect to understanding and planning urban processes. As the head of the traffic control center (SDP43) detailed,

Yeah, we would keep our traffic counts and our traffic data for years and years and years so we would be able to go back and see what way the traffic flows have changed. As part of all this we would have air and noise quality measurements and modeling which is done as well. So, yes, we would have a pretty good idea of how things have moved over the last period of time.

In addition, other time-series data continue to provide an important resource. Such data are often used in city dashboards to visualize and monitor how a city is performing over time and to simulate and forecast or predict future outcomes (Kitchin et al. 2015) or become part of the wider geoweb and spatial media (Ford and Graham 2016). Here, historical records are accessible in an instant and can be interrogated using interactive tools. In the interactive mapping system being developed by a startup entrepreneur (SDP42), he explained such an application, in this case linking very recent data (last week) to historical data (last thirty-seven years):

But coming back to the heartbeat of the city, the data that we have tells you everything that is happening in the city on a daily basis and not just what came in this morning but what happened back in 1980 . So, we could look at any building in the city, identify it, and tell you the full DNA of that building: when it was applied for permission first, when the first block was laid. ... But what that allows you to do then is analyze the city and say, how many retail applications above 10,000 square feet came in in the last week across the whole country? ... And that is where we are looking to get to, to be able to analyze the whole city and say in the last year this is where all retail went to. And then you go back to 1980 and you look at those curves and ... [tails off].

\section{Present Present}

[A smart city] is a city where you almost know in real time what is happening. You can identify problems or bottlenecks in real time and you can manage them and communicate back to citizens or various stakeholders the right information that helps them make better decisions. (SDP1, city administrator)

A significant part of the appeal of smart city technologies is their seeming ability to enable city systems to be used and managed dynamically in real time taking into account present conditions (Bleecker and Nova 2009; Kitchin 2014). Data concerning the activity and performance of an infrastructure or system are generated by sensors, actuators, transponders, and cameras and fed back to a control room for human oversight or processing by a management system that can instantaneously process and analyze data and respond as required. These data can be shared via publicly facing dashboards, application programming interfaces, and open data repositories and plugged into mobile apps. Such control rooms and dashboards seek to create instantaneous corrective actions before problems grow and multiply, to manage emergencies and conduct surveillance, and to create more efficient and optimized system operations, as well as provide accountability and transparency and a resource for civic hacking (Kitchin et al. 2015; de Lange 2018).

The increasing availability of real-time data seemingly creates an annihilation of space and time to the point where governance is enacted in a "perpetual present" (de Lange 2018). Here, temporal succession is seemingly erased to windows of short durations (Virilio 1997), with "events mapped as isolates and reduced to singularities" in which systems identify and respond to out-of-the-ordinary occurrences and dealing with the exceptional becomes routinized (de Lange 2018). For Virilio (1997), the ability to perceive and respond to distant events in the world in real time creates what he called chronoscopic time. Writing with respect to the real-time media coverage of global events and the general use of telecommunications, he argued that rather than unfolding in succession as a conventional narrative of before, during, and after or events being documented after the fact, audiences have become accustomed to the real-time instant in which narrative time implodes (Purser 2002). Constant, 24/7 media coverage creates an eternal, unfolding present of spatially and sociopolitically disconnected snapshots, with instant rather than reflective analysis. Likewise, real-time control rooms and spatial media produce chronoscopic time in which cities and personal 
time-geographies are managed in the perpetual present, responding to emerging events and serendipity. People have thus become fixated on knowing and taking part in the present-checking for new e-mails and responding, seeking out current news or weather, browsing the newest posts on social media and commenting, checking in to places on locative media, discovering when the next bus or train is due, and checking quantified self-performance metrics.

An aspect of this fixation with knowing the present is the practice of nowcasting: predicting the present, the very near future (microseconds to a few days), and the very recent past (microseconds to a couple of months; Bańbura et al. 2010). Nowcasting has been the prevalent form of weather predictionto report conditions across space at the present time and very near future based on samples at particular locations. This has recently been extended to other domains such as economic indicators to understand very recent conditions ahead of official statistics and to predict market movements and traffic flow across a road network. Likewise, predictive policing seeks to nowcast patterns of crime to direct police resources accordingly. As Uprichard $(2012,133)$ noted, the aim is often not simply to know now but "to know about now before now has happened." This is leading, she contended, to the present being increasingly embedded in institutional structures and vice versa, with the result that the "present itself becomes more and more plastic, to be stretched, manipulated, moulded and ultimately 'casted' by those who can access more of it in the supposed 'now" (133). From this perspective, urban control rooms cast the present by iteratively prefiguring it through ongoing responses.

A number of commentators have started to consider the implications and politics of real-time smart cities, arguing that a fixation on the present and speed of response creates a number of issues, such as the erasure of time for reflection and deliberation in decision making, constant connection producing time stresses, and ceding control to algorithmic systems creating forms of technocratic governance and sociospatial path dependencies (see Bleecker and Nova 2009; Uprichard 2012; Datta 2016; de Lange 2018). In essence, they challenge the emphasis on optimization, efficiency, speed, and whether now is always the right to time to act and consider the consequences of such responsiveness with regard to governmentality and quality of life. Moreover, they argue that such shifts in spatiotemporal relations need to be countered by strategies of creating space and time for asynchronous smart cities.

\section{Present Future}

Leccardi (2007) detailed that the future used to be the realm of God and nature, with society looking backward with respect to living in the present. Since the Enlightenment, he contended that society has increasingly looked instead to the future to shape the present through its own actions, with anticipation and expectation prevailing over habit, memory, and fate. Consequently, the future is not seen as an open field of possibilities but one that progresses along a contingent and relational set of path dependencies produced by society. People thus formulate strategies and plan and direct action in the short to medium term to try and realize particular futures and to forecast the future based on the present situation and certain assumptions concerning how systems work and situations might unfold socially and politically. In both cases, there is an extrapolation from the present, with the anticipation that the system under consideration will continue to work more or less as it has been. The future then is imagined and planned from the present, with current rhetoric and actions creating pathways to try and realize particular future outcomes (Adam and Groves 2007; Poli 2015).

Such future contemplations recursively affect how the present is managed to try and realize particular futures; in other words, just as the present prefigures the future, the "future acts as a determining condition of the present" (Uprichard 2012, 110). The present and the future, and the unfolding of time, are thus produced, often in highly contested ways (different factions seeking to create varying outcomes through shaping public opinion and actions, public policy, and violence). Fate, as such, takes place within a prefigured context, although there are dispositions always at work. As Poli (2015, 89) detailed, "Dispositions are facts with an anchor in the future; they are facts that can happen if the relevant triggers are activated" - a glass dropped on a hard floor will shatter; the glass might not fall, but there is always a possibility that it will.

Smart city technologies, although most often framed around managing the present, are future 
oriented with respect to plausible and preferable scenarios, dispositions, optimization, and contingency and what Adam $(2008,8)$ termed a timeprint (the temporal futures equivalent of an ecological footprint). Technologies such as flood monitoring and management seek to be reactive to the disposition of a flood, which is perhaps an infrequent possibility but a certainty if there is a certain amount of rainfall, along with other factors such as high tides. Similarly, emergency management response seeks to anticipate and react to potential dispositions, such as a terrorist event. Such an approach seeks to realize what Miller (cited in Poli 2015) termed contingency futures; that is, preparation for anticipated surprises. In contrast, a system such as a traffic control center seeks to produce optimization futures, imposing patterns and trends from the past on the future through causal predictive models (Poli 2015).

Of particular importance in how the smart city movement actively seeks to shape future urbanism and create an extended timeprint is through the practices of experimental urbanism. Here, innovators are enabled to prototype and trial new technologies in real-world settings to test, learn about, and promote possible and desirable urban futures. Smart city testbeds and living labs thus work to try and produce what Adam and Groves (2007) termed latent futures-futures in the making that are "on the way" and still have to surface and become visible (Poli 2015). In time, it is hoped that successful interventions can be scaled up to the rest of the city and translated to other cities (Evans et al. 2016). For Halpern and Günel $(2017,2)$ this shift to city districts becoming zones of experimentation involves a "particular form of spatial and temporal containment and speculation" in which "infinitely replicable but always preliminary" technological solutions are deployed. Rather than these sites moving toward places of mature and stable deployment as hoped, they remain always in the process of being updated, patched, and replaced-much like other softwaredriven technologies that have short shelf lives as new developments render them obsolete. This constant process of prototyping, Halpern and Günel (2017) argued, is a form of temporal management that aims to anticipate and respond to present and future impending threats but in a manner that consistently defers a definitive answer. On the one hand, the repetitive incompletion of experimental urbanism works to enact what Halpern and Günel
(2017) termed preemptive hope; creating a sense that an uncertain social, economic, and environmental future is being proactively tackled. On the other hand, it works to create a transition pathway to a particular vision of a smart city, not only in technological terms but also in validating and legitimating neoliberal interventions into the management of cities (Marvin and Silver 2016). Smartness thus becomes the means to imagine and respond to our future, albeit within a limited temporal horizon and through practices of "eternal and repetitive obsolescence" (Halpern and Günel 2017, 19).

\section{Future Present}

Whereas the present future extends the present into the future, the future present uses possible futures to consider and plan alternative trajectories (Adam and Groves 2007). For example, the practice of backcasting imagines a normative future-some state that we might wish to achieve-and then works back to the present to try and define the steps or pathway needed to make such a future a reality. This normative future is in contrast to other potential futures, ones that are not so desirable or contain threats and that might be realized if the present future is allowed to unfold unchecked. In this sense, Anderson (2010) argued that a normative future is evoked to preempt, prepare for, or prevent threats from being realized and to redirect present future paths onto a new trajectory. The future thus "becomes cause and justification for some form of action in the here and now" (Anderson 2010, 778). This occurs, he contended, through the assembling of styles (statements about the future that set out and limit how it should be framed and acted on), practices (acts of performing, calculating, and imagining that render the future present through materialities, epistemic objects, and affects), and logics (policies and programs through which the action in the present is enacted).

As White (2016) detailed, smart city advocates have developed a set of styles, practices, and logics that map out and draw extensively on future scenarios to both rationalize technological intervention in the present and to preempt and plan new urban trajectories. In the smart city case, White (2016) argued that three crises act as a motivator for imagining alternative futures: widespread changes in patterns of population, particularly rural to urban migration, and subsequent resource pressures; global 
climate change and the need to produce more resilient cities; and fiscal austerity and the desire to create leaner governments and attract mobile capital (also see Datta 2016). By evoking alternative future imaginaries and contrasting them to a present future that fails to take a path of smart city investment, advocates seek to preempt and prepare the ground for a new form of urbanism that will effectively respond to existing and coming crises (or at least lead to massive investment in their products).

For Poli (2015), such expectations operate as "real fictions"; they are not mere fantasies because actors develop and seek to realize plans based on them. As such, they cannot be assessed or challenged on the grounds of truth or falsehood but can only be properly opposed with respect to whether they are convincing or not. As Datta $(2016,22)$ noted, smart cities "claim to deal with the present by seizing the future. ... The future cannot be measured and called to account since it has not yet materialized." The future present smart city is thus somewhat slippery, powered by its discursive imaginaries and a smart city epistemic community and advocacy coalition that work to create convincing "logics through which anticipatory action is legitimized, guided and enacted" (Anderson 2010, 777). Such logics have appeal because city administrations and companies mostly operate in the future present, rather than being more proactive about envisioning and creating the future, as the manager of a multinational company (SDP30) stated:

[I]n our business today we are focused week to week, quarter to quarter, year to year, and then occasionally we stretch out to maybe three years, and the people in the senior leadership teams would be looking five years, but who the hell knows what it is going to be like in five years or twenty years?

Smart city imaginaries seek to remove some of this uncertainty and try to limit the multiplicity and contingency of the future. As such, smart city technologies are deployed in part "on the basis of what has not and may never happen" (Anderson 2010, 777) but in so doing prefigure the future city.

\section{Conclusion: The Smart City as Space-Time Machine}

In this article I have sought to explicate the temporality of smart cities, detailing various ways in which smart cities mediate and are mediated by temporal relations, rhythms, and modalities, using Dublin as an example. In essence, what I have done is map out the timescape of smart cities, summarized in Table 1, and its effects on spatiotemporal relations. Adam (2004) contended that within a timescape, time is multiplex in nature. Indeed, the analysis has revealed that the smart city has a "multiplicity of space-times" (May and Thrift 2001, 3) and acts as a space-time machine, producing new spatiotemporal relations in which network time, clock time, social time, natural time, past, present, and future coexist to create a new set of intersecting rhythms, beats, sequences, tempos, and temporal patterns and arrangements. The temporality of the smart city is multiple, heterogeneous, and dynamic, with numerous temporal relations and rhythms unfolding through a diverse set of contingent and relational processes that are intimately enmeshed with spatiality.

What the analysis thus highlights is that there is a need to consider in much greater detail the temporality and timescapes of smart cities and the ways in which they act as space-time machines-transforming urban spatiotemporal relations and rhythms and enacting different temporal modalities wherein the past, present, and future are evoked and utilized simultaneously but in different and sometimes paradoxical or frictional ways. Although the multiplicity of temporality detailed in Table 1 requires further elaboration and research, there are four temporal aspects of smart cities that I believe require particular attention.

First, there is a need to examine in detail what is perhaps the signature time of smart cities-realtimeness - and its nature and the consequences of city administrations operating in so-called real time. As Weltevrede et al. (2014) detailed, realtimeness is fabricated and multiple, varying across infrastructures and spatial media as function of their sociotechnical arrangements. Further, there is an unevenness in the distribution of real-time systems, with deployment in key locales first and then selective distribution to other parts of a city. Although real-time analysis and action is widely celebrated as a benefit, enabling instantaneous monitoring and control, there are also risks with focusing on the here and now, prioritizing optimization and efficiency over other considerations, and overly relying on algorithms to manage systems. A productive approach to understanding 
Table 1. The timescape of smart cities

\begin{tabular}{|c|c|c|c|c|}
\hline \multirow[t]{2}{*}{$\begin{array}{l}\text { Temporal rhythms/cycles } \\
\text { and representations }\end{array}$} & Temporal rhythms & Natural time & Social time & $\begin{array}{l}\text { Clock/measured } \\
\text { time (chronos) }\end{array}$ \\
\hline & $\begin{array}{l}\text { Cyclical and linear } \\
\text { cycles; polyrhythmic, } \\
\text { eurythmic, } \\
\text { isorhythmic, } \\
\text { arrhythmic patterns; } \\
\text { algorhythm; } \\
\text { periodicity }\end{array}$ & $\begin{array}{l}\text { Earth seasons; diurnal } \\
\text { cycles; body clocks; } \\
\text { turning of tides }\end{array}$ & $\begin{array}{l}\text { National holidays; } \\
\text { celebrations; } \\
\text { festivals; holy days; } \\
\text { working hours; rush } \\
\text { hour; family meal } \\
\text { times; timetables; } \\
\text { deadlines }\end{array}$ & $\begin{array}{l}\text { Second; minute; day; } \\
\text { week; month; year; } \\
\text { decade; century; } \\
\text { millennia; } 24 / 7\end{array}$ \\
\hline \multirow{2}{*}{$\begin{array}{l}\text { Temporal relations } \\
\text { (experienced } \\
\text { time [kairos]) }\end{array}$} & $\begin{array}{l}\text { Time-space } \\
\text { compression }\end{array}$ & Scheduling & Efficiency & Pace and tempo \\
\hline & $\begin{array}{l}\text { Time-space } \\
\text { convergence and } \\
\text { distanciation; global } \\
\text { present; instantan- } \\
\text { eous time; } \\
\text { timeless time }\end{array}$ & $\begin{array}{l}\text { Just-in-time; on-the- } \\
\text { fly; peak time; } \\
\text { sequence; } \\
\text { prioritization; } \\
\text { continuity; } \\
\text { frequency }\end{array}$ & $\begin{array}{l}\text { Saving time; } \\
\text { synchronicity; } \\
\text { latency; delay; first/ } \\
\text { second mover }\end{array}$ & $\begin{array}{l}\text { Speed; acceleration; } \\
\text { refrain; repetition; } \\
\text { duration; ahead/ } \\
\text { behind the curve; } \\
\text { statis/inertia; time } \\
\text { flies/drags; } \\
\text { fast urbanism }\end{array}$ \\
\hline \multirow[t]{2}{*}{ Temporal modalities } & Past present & Present present & Present future & Future present \\
\hline & $\begin{array}{l}\text { History; memory; } \\
\text { evolution/change; } \\
\text { trend; legacy; } \\
\text { hindcasting }\end{array}$ & $\begin{array}{l}\text { Real time; network } \\
\text { time; chronoscopic } \\
\text { time; of-the- } \\
\text { moment; } \\
\text { serendipity; always } \\
\text { on; nowcasting; } \\
\text { plastic present; } \\
\text { code/spacetime }\end{array}$ & $\begin{array}{l}\text { Forecasting; } \\
\text { speculation; } \\
\text { prediction; short/ } \\
\text { mid/long term }\end{array}$ & $\begin{array}{l}\text { Anticipation; } \\
\text { preparedness; } \\
\text { backcasting }\end{array}$ \\
\hline
\end{tabular}

the spatiotemporality of smart cities would be to unpack the pacing and fabrication of realtimeness by devices, actors, infrastructures, and activities and their social, cultural, economic, and political framing and the practices they incorporate and enable. Early examples include de Lange's (2018) examination of real-time urban dashboards and Coletta and Kitchin's (2017) unpacking of the algorhythms of a traffic control room.

Second, such research needs to be accompanied with a stronger understanding of the ways in which software and algorithms are mediating the production of space-time. Indeed, in terms of the everyday functioning of the smart city, in many cases time unfolds as what might be termed code/spacetime (extending the notion of code/space forwarded by Dodge and Kitchin [2005]), wherein space-time relations are dependent on smart city technologies to be produced in particular ways. For example, the algorhythms of a traffic control room seek to mediate the flow of traffic through junctions (sites) by altering the sequencing (timing) of traffic lights. If the code fails, in the sense of the system crashing, then the traffic lights either fail to work or operate on default settings, meaning that the space-time intended is not transduced. The production of code/ spacetime is largely an attempt to create eurythmia and to produce a consistent refrain, thus combating entropy, subversion, and breakdown. Several code/ spacetimes unfolding simultaneously produce the smart city as a polyrhythmic assemblage (Edensor 2010; Coletta and Kitchin 2017). As yet, however, we have little detailed understanding of how such realtimeness and code/spacetime work in practice.

Third, there is a pressing need for analyses of the politics of time in the smart city. New, distributed, and mobile ubiquitous computing is transforming the temporalities of cities, but whose interests do such changes serve? Do they create a more just city, or do they work for the benefit of capital and states? My analysis suggests that smart city technologies are less likely to align and subordinate their temporal 
practices to the wider tempo and temporal frames of the city; rather, they seek to influence and dominate the tempo-to proactively manage rhythm and temporal relations. In particular, they seek to produce the rhythms desired by governmentality and capital - to create a symphonic ordering of society and economy that is disciplined, controlled, and enables the practices of production (Conlon 2010; Vanolo 2014). It is the case that spatial and locative media provide individuals with temporal flexibility in scheduling, although such media operate as platform economies, with peoples' space-time movements being commodified. In other words, although citizens might benefit from the deployment of smart city technologies through enhanced optimization and efficiency of services and new apps that facilitate consumption choice and individual autonomy, this takes place within a framework of constraints that prioritize market-led solutions to urban issues, reproduce neoliberal capitalism, enforce technocratic modes of governance, and continue to perpetuate inequalities between communities. Time is thus leveraged for the benefit of some at the expense of others. As Datta and Shaban (2016b) recently argued, perhaps what the politics of time in the smart city demands is "declerated urbanism," a slowing of action and deprioritization of speed to more carefully consider "processes of democracy, citizenship, sustainability and belonging in the making of cities" to create a more just smart city.

Finally, the timescape discussed in this article has been mapped out through an analysis of smart city initiatives in Dublin, Ireland. Although it is likely that very similar timescapes operate within other Global North cities, undoubtedly there is local variation due to varying context, such as culture, history, governance, economy, and so on. These variances might be amplified with respect to the Global South. As the collection of essays in Datta and Shaban (2016a) highlight with respect to cities in Africa, Asia, and the Middle East, speed is very much of the essence in the race to transition from majority rural to urban populations. While Dublin is gripped in slow urban development, with a sluggish planning system and only a few thousand new housing units being built per annum despite demand, many Global South cities are growing by tens of thousands of units, accompanied by massive infrastructure projects, aimed at fast-forwarding, future proofing, and leapfrogging economic and population development phases (Datta 2018). Moreover, other forms of time are at play. For example, in relation to India, Datta (2018) contends that there is the simultaneous production of postcolonial time and precolonial mythical time in the drive to create 100 smart cities, with the astrological, religious, and mythological being used by the state to promote a nationalist urban agenda. She noted that despite claims to speed, efficiency, and rationality, the postcolonial modernity of India's fast urbanism is marked by an "ambiguity between rational and mythological time, between linear and cyclical notions of progress and development, and between technocratic and mythological nationhood" (3). There is thus a need to unpack and compare the temporalites and timescapes of smart cities and how they act as space-time machines within different locales globally.

\section{Acknowledgment}

Many thanks to Claudio Coletta for comments on an earlier draft of this article.

\section{Funding}

The research for this article has been conducted under the Programmable City project, funded by a European Research Council Advanced Investigator award (ERC-2012-AdG-323636-SOFTCITY).

\section{ORCID}

Rob Kitchin (D) http://orcid.org/0000-0003-4458-7299

\section{References}

Adam, B. 2004. Time. Cambridge, UK: Polity.

. 2007. Foreword. In 24/7: Time and temporality in the network society, ed. R. Hassan and R. Purser, ix-xii. Stanford, CA: Stanford University Press.

. 2008. Of timespaces, futurescapes and timeprints. Presentation at Lüneburg University, Lüneburg, Germany. http://www.cardiff.ac.uk/socsi/futures/conf_ ba_lueneberg170608.pdf.

Adam, B., and C. Groves. 2007. Future matters. Leiden, The Netherlands: Brill.

Anderson, B. 2010. Preemption, precaution, preparedness: Anticipatory action and future geographies. Progress in Human Geography 34 (6):777-98.

Bańbura, M., D. Giannone, and L. Reichlin. 2010. Nowcasting. European Central Bank Working Paper 
No. 1275. Accessed July 9, 2018. https://www.econstor. eu/bitstream/10419/153709/1/ecbwp1275.pdf.

Bleecker, J., and N. Nova. 2009. Asynchronicity: Design fictions for asynchronous urban computing. New York: Situated Technologies.

Breathnach, P. 1998. Exploring the "Celtic tiger" phenomenon: Causes and consequences of Ireland's economic miracle. European Urban and Regional Studies 5 (4):305-16.

-2000. Globalisation, information technology, and the emergence of "'niche" transnational cities: The growth of the call centre sector in Dublin. Geoforum $31(4): 477-85$.

Cairncross, F. 1997. The death of distance: How the communications revolution will change our lives. Boston: Harvard Business School Press.

Castells, M. 1996. Rise of the network society. Oxford, UK: Blackwell.

Coletta, C., L. Heaphy, and R. Kitchin. 2018. From the accidental to articulated smart city: The creation and work of "Smart Dublin." European Urban and Regional Studies. Advance online publication. doi:10.1177/ 0969776418785214.

Coletta, C., and R. Kitchin. 2017. Algorhythmic governance: Regulating the "heartbeat" of a city using the Internet of things. Big Data and Society 4 (2): 1-16.

Conlon, D. 2010. Fascinatin' rhythm(s): Polyrhythmia and the syncopated echoes of the everyday. In Geographies of rhythm: Nature, place, mobilities and bodies, ed. T. Edensor, 71-81. Farnham, UK: Ashgate.

Crang, M. 2001. Rhythms of the city: Temporalised space and motion. In Timespace: Geographies of temporality, ed. J. May and N. Thrift, 187-207. London and New York: Routledge.

- 2007. Speed $=$ distance/time chronotopographies of action. In 24/7: Time and temporality in the network society, ed. R. Hassan and R. Purser, 62-88. Stanford, CA: Stanford University Press.

Datta, A. 2015. New urban utopias of postcolonial India: "Entrepreneurial urbanization" in Dholera smart city, Gujarat. Dialogues in Human Geography 5 (1):3-22.

. 2016. Introduction: Fast cities in an urban age. In Mega-urbanization in the Global South: Fast cities and new urban utopias of the postcolonial state, ed. A. Datta and A. Shaban, 1-27. London and New York: Routledge.

- 2018. Postcolonial urban futures: Imagining, governing and reclaiming India's urban age. Environment and Planning D: Society and Space. Advance online publication. doi: 10.1177/0263775818800721

Datta, A., and A. Shaban, eds. 2016a. Mega-urbanization in the Global South: Fast cities and new urban utopias of the postcolonial state. London and New York: Routledge.

2016b. Slow: Towards a decelerated urbanism. In Mega-urbanization in the Global South: Fast cities and new urban utopias of the postcolonial state, ed. A. Datta and A. Shaban, 205-20. London and New York: Routledge.

de Lange, M. 2018. From real-time city to asynchronicity: Exploring temporalities of smart city dashboards. In Time for mapping: Cartographic temporalities, ed.
S. Lammes, C. Perkins, A. Gekker, S. Hind, C. Wilmott, and D. Evans, 238-55. Manchester, UK: Manchester University Press.

de Lange, M., and M. de Waal. 2013. Owning the city: New media and citizen engagement in urban design. First Monday 18 (11). Accessed February 1, 2017. http://firstmonday.org/ojs/index.php/fm/article/ view/4954.

de Waal, M. 2014. The city as interface: How digital media are changing the city. Rotterdam, The Netherlands: nai010.

Dodge, M., and R. Kitchin. 2000. Mapping cyberspace. London and New York: Routledge.

. 2005. Code and the transduction of space. Annals of the Association of American Geographers 95 (1):162-80.

. 2007. Outlines of a world coming in existence: Pervasive computing and the ethics of forgetting. Environment and Planning B: Planning and Design 34 (3):431-45.

Dodgshon, R. A. 2008. Geography's place in time. Geografiska Annaler B 90 (1):1-15.

Edensor, T., ed. 2010. Geographies of rhythm: Nature, place, mobilities and bodies. Farnham, UK: Ashgate.

Elwood, S., and A. Leszczynski. 2013. New spatial media, new knowledge politics. Transactions of the Institute of British Geographers 38 (4):544-59.

Evans, J., A. Karvonen, and R. Raven. 2016. The experimental city: New modes and prospects of urban transformation. In The experimental city, ed. J. Evans, A. Karvonen, and R. Raven, 1-12. London and New York: Routledge.

Ford, H., and M. Graham. 2016. Semantic cities: Coded geopolitics and the rise of the semantic Web. In Code and the city, ed. R. Kitchin and S.-Y. Perng, 200-214. London and New York: Routledge.

Foth, M., ed. 2009. Handbook of research on urban informatics: The practice and promise of the real-time city. Hershey, PA: Information Science Reference, IGI Global.

Giddens, A. 1984. The constitution of society: Outline of the theory of structuration. Berkeley: University of California Press.

Giffinger, R., and N. Pichler-Milanović. 2007. Smart cities: Ranking of European medium-sized cities. Vienna, Austria: Centre of Regional Science, Vienna University of Technology.

Gillespie, T. 2014. The relevance of algorithms. In Media technologies: Essays on communication, materiality, and society, ed. T. Gillespie, P. Boczkowski, and K. Foot, 167-93. Cambridge, MA: MIT Press.

Graham, S., and S. Marvin. 2001. Splintering urbanism: Networked infrastructures, technological mobilities and the urban condition. London and New York: Routledge.

Graham, S. D. N. 2005. Software-sorted geographies. Progress in Human Geography 29 (5):562-80.

Hägerstrand, T. 1970. What about people in regional science? Papers of the Regional Science Association 24 (1):6-21.

Halpern, O., and G. Günel. 2017. Demoing unto death: Smart cities, environment, and preemptive hope. Fibreculture 29: 1-23 doi:10. 15307/fcj.29.215.2017 
Hassan, R. 2003. Network time and the new knowledge epoch. Time and Society 12 (2-3):226-41.

- 2007. Network time. In 24/7: Time and temporality in the network society, ed. R. Hassan and R. Purser, 37-61. Stanford, CA: Stanford University Press.

Hassan, R., and R. Purser. 2007. Introduction. In 24/7: Time and temporality in the network society, ed. R. Hassan and R. Purser, 1-24. Stanford, CA: Stanford University Press.

Janelle, D. 1968. Central place development in a timespace framework. The Professional Geographer 20 (1):5-10.

Kinsley, S. 2015. Memory programmes: The industrial retention of collective life. Cultural Geographies 22 (1):155-75.

Kitchin, R. 2014. The real-time city? Big data and smart urbanism. GeoJournal 79 (1):1-14.

- 2016. The ethics of smart cities and urban science. Philosophical Transactions A 374:20831-15.

Kitchin, R., and B. Bartley. 2007. Ireland in the twentyfirst century. In Understanding contemporary Ireland, ed. B. Bartley and R. Kitchin, 1-26. London: Pluto.

Kitchin, R., T. Lauriault, and G. McArdle. 2015. Knowing and governing cities through urban indicators, city benchmarking and real-time dashboards. Regional Studies, Regional Science 2 (1):6-28.

Kitchin, R., T. Lauriault, and M. Wilson. 2017. Understanding spatial media. In Understanding spatial media, 1-21. London: Sage.

Leccardi, C. 2007. New temporal perspectives in the "high-speed society." In 24/7: Time and temporality in the network society, ed. R. Hassan and R. Purser, 25-36. Stanford, CA: Stanford University Press.

Lefebvre, H. 2004. Rhythmanalysis: Space, time and everyday life, trans. S. Elden and G. Moore. Paris: Editions Syllepse.

Leszczynski, A. 2015a. Spatial big data and anxieties of control. Environment and Planning D: Society and Space 33 (6):965-84.

- 2015b. Spatial media/tion. Progress in Human Geography 39 (6):729-51.

Luque-Ayala, A., and S. Marvin. 2016. The maintenance of urban circulation: An operational logic of infrastructural control. Environment and Planning D: Society and Space 34 (2):191-208.

Marvin, S., and J. Silver. 2016. The urban laboratory and emerging sites of urban experimentation. In The experimental city, ed. J. Evans, A. Karvonen, and R. Raven, 47-60. London and New York: Routledge.

Marx, K. 1857. Grundrisse: Foundations of the critique of political economy. Harmondsworth: Penguin.

Massey, D. 1992. Politics and space/time. New Left Review 196:65-84.

Mattern, S. 2017. Code and clay, data and dirt: Five thousand years of urban media. Minneapolis: University of Minnesota Press.

May, J., and N. Thrift, eds. 2001. Timespace: Geographies of temporality. London and New York: Routledge.

Miyazaki, S. 2012. Algorhythmics: Understanding micro-temporality in computational cultures. Computational Culture 2. Accessed December 18, 2017. http://computationalculture.net/article/algorhythmics- understanding-micro-temporality-in-computationalcultures.

Parkes, D., and N. Thrift. 1980. Times, spaces and places: A chronogeographic perspective. Chichester, UK: Wiley.

Poli, R. 2015. Social foresight. On the Horizon 23 (2):85-99.

Purser, R. 2002. Contested presents: Critical perspectives on "real-time" management. In Making time: Time in modern organizations, ed. B. Adam, R. Whipp, and I. Sabelis, 155-67. Oxford, UK: Oxford University Press.

Rosa, H. 2003. Social acceleration: Ethical and political consequences of a desynchronized high-speed society. Constellations 10 (1):3-33.

Rose, G. 2017. Posthuman agency in the digitally mediated city: Exteriorization, individuation, reinvention. Annals of the American Association of Geographers 107 (4):779-93.

Shwayri, S. T. 2016. Turning over a new lead: Sustainability and urban experimentation in Seoul. In The experimental city, ed. J. Evans, A. Karvonen, and R. Raven, 181-94. London and New York: Routledge.

Shelton, T., M. Zook, and A. Wiig. 2015. The actually existing smart city. Cambridge Journal of Regions, Economy and Society $8(1): 13-25$.

Southerton, D., and M. Tomlinson. 2005. Pressed for time-The differential impacts of a time squeeze. The Sociological Review 53 (2):215-40.

Sutko, D., and A. de Souza e Silva. 2011. Location-aware mobile media and urban sociability. New Media 8 Society 13 (5):807-23.

Thrift, N., and S. French. 2002. The automatic production of space. Transactions of the Institute of British Geographers 27 (3):309-35.

Uprichard, E. 2012. Being stuck in (live) time: The sticky sociological imagination. The Sociological Review 60 (Suppl. 1):124-38.

Vanolo, A. 2014. Smartmentality: The smart city as disciplinary strategy. Urban Studies 51 (5):883-98.

Virilio, P. 1997. Open sky. London: Verso.

Wajcman, J. 2008. Life in the fast lane? Towards a sociology of technology and time. The British Journal of Sociology 59 (1):59-77.

Weltevrede, E., Helmond, A. A., and C. Gerlitz. 2014. The politics of real-time: A device perspective on social media and search engines. Theory, Culture and Society 31 (6):125-50.

White, J. 2016. Anticipatory logics of the smart city's global imaginary. Urban Geography 37 (4):572-89.

Willis, K. S. 2016. Netspaces: Space and place in a networked world. Farnham, UK: Ashgate.

Wilson, M. W. 2012. Location-based services, conspicuous mobility, and the location-aware future. Geoforum 43 (6):1266-75.

ROB KITCHIN is a Professor in the Department of Geography and Maynooth University Social Sciences Institute, National University of Ireland Maynooth, County Kildare, W23 F2H6, Ireland. E-mail: Rob.Kitchin@mu.ie. His research interests include the creation, politics, and ethics of smart cities and the development and praxes of spatial media and urban dashboards. 